\section{Copper isotope evidence for large-scale sulphide fractionation during Earth's differentiation}

\section{P.S. Savage ${ }^{1,2,3^{*}}$, F. Moynier ${ }^{1}$, H. Chen ${ }^{4}$} G. Shofner ${ }^{1}$, J. Siebert ${ }^{1}$, J. Badro' ${ }^{1}, 5$, I.S. Puchtel ${ }^{6}$

\section{Abstract}

doi: 10.7185/geochemlet.1506

The differentiation of Earth into a metallic core and silicate mantle left its signature on the chemical and isotopic composition of the bulk silicate Earth (BSE). This is seen in the depletion of siderophile (metal-loving) relative to lithophile (rock-loving) elements in Earth's mantle as well as the silicon isotope offset between primitive meteorites (i.e. bulk Earth) and BSE, which is generally interpreted as a proof that $\mathrm{Si}$ is present in Earth's core. Another putative light element in Earth's core is sulphur; however, estimates of core $\mathrm{S}$ abundance vary significantly and, due to its volatile nature, no unequivocal $\mathrm{S}$ isotopic signature for core fractionation has thus far been detected. Here we present new high precision isotopic data for $\mathrm{Cu}$, a chalcophile (sulphur-loving) element, which shows that Earth's mantle is isotopically fractionated relative to bulk Earth. Results from high pressure equilibration experiments suggest that the sense of $\mathrm{Cu}$ isotopic fractionation between BSE and bulk Earth requires that a sulphide-rich liquid segregated from Earth's mantle during differentiation, which likely entered the core Such an early-stage removal of a sulphide-rich phase from the mantle presents a possible solution to the long-standing $1^{\text {st }}$ terrestrial lead paradox.

Received 18 March 2015 | Accepted 10 April 2015 | Published 4 June 2015

1. Institut de Physique du Globe de Paris, Institut Universitaire de France, Sorbonne Paris Cité - Université Paris Diderot, UMR CNRS 7154, 1 rue Jussieu, 75005 Paris, France

Department of Earth Sciences, Durham University, Science Labs, Durham DH1 3LE, UK

Department of Earth and Environmental Sciences, University of St. Andrews, Irvine Building St. Andrews, KY16 9AL, UK

Corresponding author: p.s.savage@dur.ac.uk

Department of Earth and Planetary Sciences and McDonnell Center for the Space Sciences, Washington University in St. Louis, One Brookings Drive, St. Louis, MO 63130, USA

Earth and Planetary Science Laboratory, Ecole Polytechnique Federale de Lausanne, CH-1015 Lausanne, Switzerland

6. Department of Geology, University of Maryland, College Park, Maryland 20742, USA

The budget of light elements in Earth's core is a long-standing geochemical problem (Poirier, 1994), as constraining such elements and their abundances can tell us much about the physiochemical conditions of Earth's differentiation. Sulphur is often cited as one such element: cosmochemical estimates suggest that the core contains $\sim 2$ wt. \% S (Dreibus and Palme, 1996); sulphur in the core is seemingly necessary to explain mantle W and Mo abundances (Wade et al., 2012) and can explain the disparity between the radiometric $\mathrm{Pb}$ and $\mathrm{W}$ isotope ages of the mantle (Wood and Halliday, 2005). However, recent molecular dynamics estimates suggest $\mathrm{S}$ may not be present at all in the core (Badro et al., 2014); also, it is unclear as to whether $\mathrm{S}$ entered the core as an iron alloy, or as a discrete sulphide phase (O'Neill, 1991). Further complications stem from the fact that late addition of extra-terrestrial $\mathrm{S}$ to the mantle, post-core formation, should overwhelm any pre-existing S (isotope) signature (the "late veneer"; Holzheid et al., 2000; Wang et al., 2013). In an effort to investigate the role of S during Earth's differentiation, we have investigated the $\mathrm{Cu}$ isotope compositions of bulk Earth and BSE; this is because $\mathrm{Cu}$ is siderophile and strongly chalcophile ( 2/3 of Earth's $\mathrm{Cu}$ is thought to be in the core; Palme and O'Neill, 2014, McDonough, 2003) but is less volatile than S, so is abundant enough in Earth's mantle to have been largely unaffected by a late veneer.

To begin with, it was necessary to obtain robust $\mathrm{Cu}$ isotope compositions for both BSE and bulk Earth. To this end, we measured the $\mathrm{Cu}$ isotope composition of 88 extra-terrestrial and terrestrial samples using high precision multi-collector inductively coupled plasma mass spectrometry (MC-ICPMS; see Supplementary Information for methods and data tables) and combined these results with pre-existing literature data.

Choosing samples to constrain the $\mathrm{Cu}$ isotope composition of BSE is not trivial, due to the specific behaviour of $\mathrm{Cu}$ during mantle melting. The concentration of $\mathrm{Cu}$ in a mantle melt is predominantly controlled by the consumption of sulphide phases by such a melt (Lee et al., 2012). If melt fraction remains below $\sim 25 \%$, residual sulphides should retain $\mathrm{Cu}$, which could potentially give rise to isotopic fractionation. With this in mind, two lithologies were initially chosen to constrain the copper isotopic composition of BSE. The first were komatiites, mantle-derived ultramafic lavas generated by high degrees ( $>25 \%$ ) of mantle melting and typically found in Archaean terrains (Arndt, 2008). In this study, we analysed komatiite samples from two localities; 2.4 Ga Vetreny Belt (Baltic Shield) and 2.7 Ga Belingwe (South Africa). The second were "fertile" orogenic lherzolites from Lanzo (Italy) and Horoman (Japan); that is, samples of the mantle that appear to have undergone little to no melt depletion. These data were augmented by $\mathrm{Cu}$ isotope analyses of mid-ocean ridge basalts (MORB), which are typically formed by fairly high (10-15\%) degrees of melting of upper mantle. We also include data from a variety of ocean island basalt samples to investigate the possibility of $\mathrm{Cu}$ isotope mantle heterogeneities (see Supplementary Information for all sample information). 


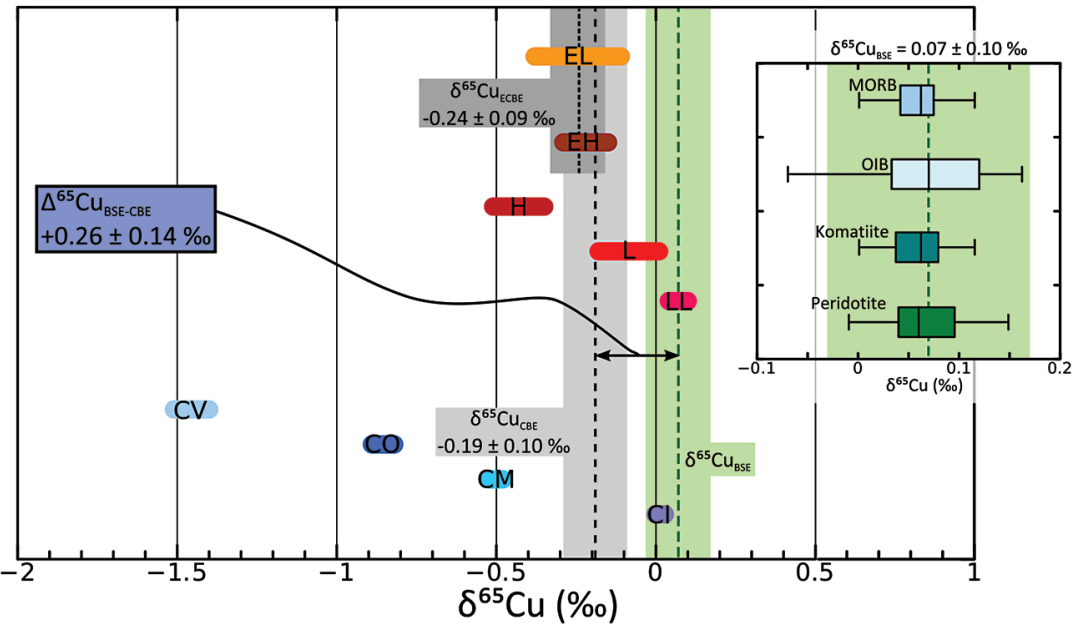

Figure 1 Copper isotope range of the primitive (chondritic) meteorite groups. Inset: Box and whisker plot showing the range of $\mathrm{Cu}$ isotope compositions for the terrestrial samples used in constraining the BSE Cu isotope composition. Green box and dotted line represents the composition of BSE, light grey box and long dashes represent the composition of "chondritic bulk Earth" (CBE), dark grey box and short dashes represent the composition of "enstatite chondrite bulk Earth" (ECBE). Errors on the estimates are all 2 s.d.

The $\mathrm{Cu}$ isotope compositions of terrestrial basalts and ultramafic rocks define a limited range $\left(-0.07 \%\right.$ o $<\delta^{65} \mathrm{Cu}<+0.16 \%$; Fig. $1, \delta^{65} \mathrm{Cu}=\left[{ }^{65} \mathrm{Cu} /{ }^{63} \mathrm{Cu}_{\text {sample }} /\right.$ $\left.\left.{ }^{65} \mathrm{Cu} /{ }^{63} \mathrm{Cu}_{\text {std. }}.\right)-1\right] \times 1000$; where std. is NIST SRM976). Despite the potential for $\mathrm{Cu}$ isotope fractionation through sulphide retention, each sample group is statistically identical and the data are normally distributed (Supplementary Information), providing a robust and precise average BSE Cu isotope composition of $\delta^{65} \mathrm{Cu}_{\mathrm{BSE}}=0.07 \pm 0.10 \%$ o (2 s.d. $)$.

It is of course impossible to obtain a sample of the 'bulk Earth' and hence, like many studies before ours, we assume that bulk Earth formed from primitive (chondritic) meteorites (e.g., Palme and O'Neill, 2014). The issue then is to decide which group(s) of meteorites best represents Earth, in terms of its $\mathrm{Cu}$ budget. This is particularly important, as the range of chondrite $\mathrm{Cu}$ isotope compositions span a wide range $\left(-1.45 \% \circ<\delta^{65} \mathrm{Cu}<+0.07 \%\right.$, Fig. 1; Luck et al., 2005), thus we now discuss a number of model-dependent scenarios.

a) The Earth's Cu budget was established early in Earth's accretion Like $\mathrm{Cu}$, large isotope variations also exist in systems such as $\mathrm{O}, \mathrm{Ti}$, $\mathrm{Cr}, \mathrm{Ru}, \mathrm{Ca}$ etc., suggesting that no single chondrite group represents a perfect match to Earth, and many workers posit a mixture. Based on modelling of Fitoussi and Bourdon (2012), we calculate a chondritic bulk Earth (CBE) value of $\delta^{65} \mathrm{Cu}_{\mathrm{CBE}}=-0.19 \pm 0.10 \%$ o (2 s.d., Fig. 1). Another approach is to utilise the enstatite chondrites; despite being chemically dissimilar, these meteorites are identical to the Earth for most isotope systems (Dauphas et al., 2014) and many models suggest that the material that accreted to form the Earth contained a large proportion of enstatite chondrite-like planetesimals (Dauphas et al., 2014). Both enstatite chondrites groups have similar ranges as well as having identical $\delta^{65} \mathrm{Cu}$ values (Fig. 1); a mixture of $\mathrm{EH}$ and EL chondrites gives an enstatite chondrite bulk Earth (ECBE) of $\delta^{65} \mathrm{Cu}=-0.24$ $\pm 0.09 \%$ o (2 s.d., Fig. 1), identical to $\delta^{65} \mathrm{Cu}_{\mathrm{CBE}}$.

b) The Earth's Cu was delivered late, as a result of the Moon-forming giant impact: The mantle budget of $\mathrm{Cu}$ and other moderately volatile elements may be dominated by the final $10 \%$ of material accreted to Earth, associated for example with the Moon-forming giant impactor, Theia (Albarède, 2009). The $\mathrm{Cu}$ in the mantle, therefore, would have escaped the effects of all but the final stages of planetary differentiation, as Hf-W isotope data suggests that the majority of the core had formed by the time of impact (Kleine et al., 2010). Work on Ag isotopes by Schönbächler et al. (2010) seemed to indicate that the impactor material was dominated by CI-like material. If this is the case, then our data would seem to support their model; our estimate for BSE is almost identical to the $\mathrm{Cu}$ isotope composition of $\mathrm{CI}$ chondrites. However, more recent isotope data seems to rule out a CI-like impactor; in particular, precise lunar $\mathrm{O}$ isotope data suggests that the impactor had an enstatite chondrite isotope signature (Herwartz et al., 2014). In this instance, again, the enstatite chondrite model would seem most representative of bulk Earth.

Accepting either model ' $a$ ' or ' $b$ ' above, the bulk Earth Cu isotope composition lies somewhere between $\delta^{65} \mathrm{Cu}=-0.19 \pm 0.10 \%$ and $-0.24 \pm 0.09 \%$. Therefore, in terms of $\mathrm{Cu}$ isotopes, BSE is enriched in the heavy $\mathrm{Cu}$ isotope compared to bulk Earth, with a minimum offset (taking bulk Earth to be $-0.19 \%$ o) of $+0.26 \pm 0.14 \%$ o ( 2 s.d., Fig. 1$)$. This suggests that some process related to planetary differentiation and accretion has affected the $\mathrm{Cu}$ isotope composition of Earth's mantle; we now consider the two most likely culprits: volatile loss of $\mathrm{Cu}$, and core formation.

Preferential removal of the lighter $\mathrm{Cu}$ isotope during volatile loss could lead to enrichment in isotopically heavy Cu in Earth's mantle. This, however, can be discounted by considering the $\mathrm{Zn}$ isotope system. Zinc is more volatile and less siderophile/chalcophile than $\mathrm{Cu}$ (Lodders, 2003); like all moderately volatile, lithophile elements, Earth's mantle is depleted in Zn compared to most chondrite groups suggesting partial loss or incomplete accretion (Palme and $\mathrm{O}^{\prime} \mathrm{Neill}, 2014$ ). However, the bulk Earth $\mathrm{Zn}$ isotope composition is equal to or lighter than those same meteorites (Albarède, 2009; Chen et al., 2013), i.e. contrary to the isotope effect predicted by volatile loss. Hence whichever process(es) resulted in the volatility-related depletion of $\mathrm{Zn}$ in Earth's mantle did not affect its isotopes. It is therefore unlikely that such a process can explain the heavy $\mathrm{Cu}$ isotope enrichment in BSE. 
Planetary differentiation is therefore the most likely explanation for the $\mathrm{Cu}$ isotope difference between BSE and bulk Earth. To further investigate the behaviour of $\mathrm{Cu}$ isotopes during core formation, i.e. metal-silicate and sulphidesilicate equilibration, we performed a preliminary series of high-pressure, high temperature experiments wherein natural basalt rock powder, doped with $\mathrm{Cu}$ (as either metal or oxide) was equilibrated with either pure Fe metal or stoichiometric FeS under fully molten conditions (see Supplementary Information). In the metal-silicate experiments, the direction of isotopic fractionation between the two phases $\left({ }^{65} \mathrm{Cu}_{\text {metal-silicate }}\right)$ was always slightly positive, varying little with temperature $(\sim+0.1 \%)$. Crucially, in the sulphide-silicate experiments the sense of fractionation is negative, opposite and with a larger magnitude to that of metalsilicate equilibration $(>-0.5 \%$ ). These data agree with the sense of $\mathrm{Cu}$ isotope fractionation between metal, silicate and sulphide measured in iron meteorites (Williams and Archer, 2011), as well as the extremely light $\mathrm{Cu}$ isotope compositions measured in secondary sulphide minerals (Markl et al., 2006). Therefore, the positive $\mathrm{Cu}$ isotope difference between BSE and bulk Earth cannot be due to metal-silicate fractionation, because the isotopic fractionation has the incorrect sense. Instead, Earth's "missing" light Cu must be stored in a sulphide-rich reservoir.

Mantle sulphides are a potential explanation; however, given the relative $\mathrm{Cu}$ isotope homogeneity of mantle-derived lithologies (Fig. 1) as well as the fact that a typical peridotite contains $>90 \%$ of its $\mathrm{Cu}$ in sulphides (Lee et al., 2012), this requires that a relatively significant budget of $\mathrm{Cu}$ is stored in sulphides that are never sampled by mantle melting or by tectonic exhumation. This does not seem to be the case: for instance, komatiites, which formed via high degrees of partial melting (such that at least $95 \%$ of the $\mathrm{Cu}$ in the mantle source should be transferred to the melt), have $\mathrm{Cu}$ isotope compositions equal to that of orogenic lherzolites, which are (arguably) direct samples of the mantle. Komatiites also provide a temporal view on mantle composition and suggest that the $\mathrm{Cu}$ isotope composition of BSE was established at least as far back as $2.7 \mathrm{Ga}$, the age of our oldest sample. Similarly, ocean island basalts, which potentially sample sulphide-rich pyroxenites, show no evidence for significant $\mathrm{Cu}$ isotope mantle heterogeneity (Fig. 1). The lower continental crust is also a possible reservoir for isotopically light $\mathrm{Cu}$ sulphides - however, even if the bulk $\mathrm{Cu}$ concentration in the lower continental crust was three times current estimates, it would only represent $\sim 0.6$ wt. \% of BSE Cu and so would require an unfeasibly light composition $\left(\delta^{65} \mathrm{Cu}\right.$ $<-40 \%$ o). Hence, sulphides in the mantle or crust may host some isotopically light $\mathrm{Cu}$, but are apparently not abundant enough to account for the significant $\mathrm{Cu}$ isotope offset between BSE and bulk Earth.

An alternative explanation is the early-stage formation of a sulphide-rich (Fe-O-S) liquid in the mantle, as the final volatile-rich residue after crystallisation of a magma ocean; this is often called the "Hadean Matte" (HM; Fig. 2; O'Neill, 1991). Given its higher density compared to ambient mantle, a HM should pond at the core/mantle boundary and, potentially, admix into the core, isolating it from subsequent re-equilibration. Such a reservoir has been invoked to explain

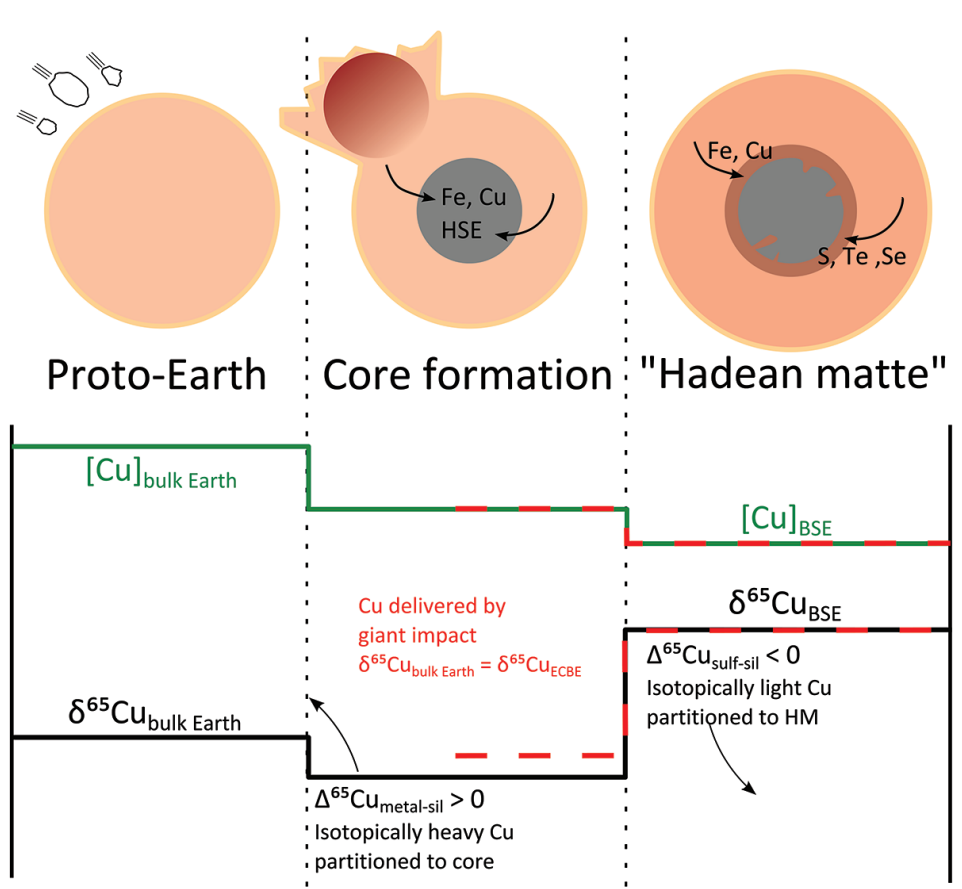

Figure 2 Schematic evolution of Cu concentration and isotopic composition of Earth's mantle as modelled in this contribution. Earth accretes as a mixture of chondrites such that the bulk Earth $\mathrm{Cu}$ isotope composition is $\delta^{65} \mathrm{Cu}_{\mathrm{CBE}}$. Core formation sequesters $~ 60 \%$ of Earth's $\mathrm{Cu}$ in the metal phase, which is enriched in the heavy isotope, driving Earth's mantle to a lighter composition. The formation of a Fe-O-S layer, the "Hadean Matte", sequesters isotopically light $\mathrm{Cu}$, driving Earth's mantle to its present day composition ( $\left.{ }^{65} \mathrm{Cu}_{\mathrm{BSE}}\right)$. Alternatively, $\mathrm{Cu}$ is delivered by an enstatite chondrite-like Giant Impactor, and mantle $\mathrm{Cu}$ only experiences sulphide-silicate equilibration.

moderately siderophile element abundances in the mantle ( $\mathrm{O}^{\prime}$ Neill, 1991) and the mismatch of various core formation chronometers (Wood and Halliday, 2005), and could host significant amounts of $\mathrm{Cu}$. To this end, we have attempted to calculate the mass and composition of a Hadean Matte needed to balance the $\mathrm{Cu}$ isotope offset between BSE and bulk Earth. Following previous models, the HM should form after segregation of the majority ( $99 \%$ ) of the core; as such we have used a simple two-stage model, starting from a chondritic $\left(\delta^{65} \mathrm{Cu}_{\mathrm{CBE}}\right)$ proto-Earth, where $\mathrm{Cu}$ is first partitioned into the core (metal-silicate equilibration), then a sulphide phase (Fig. 2). This is based on model 'a' above, i.e. Earth's Cu budget was established early in Earth's accretion. Assuming instead that Earth's mantle $\mathrm{Cu}$ was delivered by an enstatite chondrite-like Giant impactor (model ' $b$ ' above) does not significantly change the modelling, except that mantle $\mathrm{Cu}$ does not experience major metal-silicate equilibration, only sulphide-silicate equilibration (Fig. 2) 
A condition of the model ' $a$ ' is that the Cu normally assumed to be in Earth's core is now apportioned between $\mathrm{HM}$ and core. Fixing a range of likely $\mathrm{Cu}$ concentrations in the $\mathrm{HM}$, we calculated the remaining core $[\mathrm{Cu}]$ as a function of HM mass (or thickness, assuming a fixed density). This relationship is shown in Figure $3 \mathrm{a}$, wherein the amount of $\mathrm{Cu}$ in the core reduces as the HM thickness and $\mathrm{Cu}$ concentration increases. The value of $[\mathrm{Cu}]_{\text {core }}$ should not fall below $120 \mathrm{ppm}$ because $\mathrm{Cu}$ is also siderophile (Siebert et al., 2013), which predicts a maximum HM thickness of $\sim 35 \mathrm{~km}$.

We then calculated the $\mathrm{Cu}$ isotope composition for each HM scenario required to drive the equilibrating silicate (i.e. the mantle) towards the modernday BSE value. This is shown in Figure $3 b$, where a smaller HM results in a more negative $\mathrm{HM} \mathrm{Cu}$ isotope composition. We calculate a range of $\mathrm{HM} \mathrm{Cu}$ isotope compositions because our preliminary experiments were simply used to assess the sense, not the magnitude of isotope fractionation; however, because large isotope fractionations $(>2 \%$ o) are not expected at the temperatures associated with the formation of a HM (3000-4000 K), a minimum thickness of $\sim 2 \mathrm{~km}$ is predicted, even for the most $\mathrm{Cu}$-rich HM. The maximum size for each $\mathrm{HM}$ as controlled by its $\mathrm{Cu}$ concentration corresponds to a minimum $\Delta^{65} \mathrm{Cu}_{\text {sulphide-silicate value of }}$ $\sim-0.6 \%$. To further constrain this model, further work is required to accurately parameterise $\mathrm{Cu}$ isotope fractionation factors, but these model predictions are in general agreement with our experimental data (Supplementary Information).

Admixing a Fe-O-S liquid into Earth's core will affect core composition, specifically with regard to the light elements $\mathrm{S}$ and $\mathrm{O}$. Given the constraints provided above (HM mass $\leq 1.6 \%$ of Earth's core), addition of a HM to the core will have a small effect on the core O composition (< 0.25 wt. \% addition); for $\mathrm{S}$, the effect is more significant - our model suggests that up to $\sim 0.5 \mathrm{wt}$. \% $\mathrm{S}$ could be added (Fig. 3a), which is in line with recent estimates based on molecular dynamics (Badro et al., 2014) and siderophile element partitioning studies (Siebert et al., 2013) - of course, this does not preclude further core addition of $S$ as a metal alloy.

Finally, we estimate the effect that removal of the HM could have on mantle lead isotope composition. Lead can be strongly chalcophile, and an early fractionation of isotopically primitive $\mathrm{Pb}$ by a sulphide-rich phase is often cited as a solution to the $1^{\text {st }}$ terrestrial $\mathrm{Pb}$ paradox; that is, the observation that, in ${ }^{206} \mathrm{~Pb} /{ }^{204} \mathrm{~Pb}$ vs. ${ }^{207} \mathrm{~Pb} /{ }^{204} \mathrm{~Pb}$ space, most mantle-derived rocks, continental sediments etc. plot to the right of the terrestrial geochron (either the meteoritic, $4.568 \mathrm{Ga}$ geochron or the later Hf-W core formation cessation age of $\sim 4.53 \mathrm{Ga}$, Fig. 4; Kramers and Tolstikhin, 1997). Modelling the evolution of mantle $\mathrm{Pb}$ isotope composition resulting from two fractionation events, metal-silicate equilibration at $50 \mathrm{Ma}$ and sulphide-silicate equilibration at $100 \mathrm{Ma}$ (following Galer and Goldstein 1996; see Supplementary Information for details), predicts a present-day mantle $\mathrm{Pb}$ isotopic composition that is comparable to empirical estimates for BSE, albeit the more unradiogenic ones (Fig. 4; Halliday, 2004) as well as the Pb composition of the ancient primitive mantle as estimated using flood basalts (Jackson and Carlson, 2011). Therefore, this does not preclude further unradiogenic $\mathrm{Pb}$ reservoirs, such as sulphides in refractory mantle phases (Burton et al., 2012) or late accretion of mantle $\mathrm{Pb}$ (Albarède, 2009).
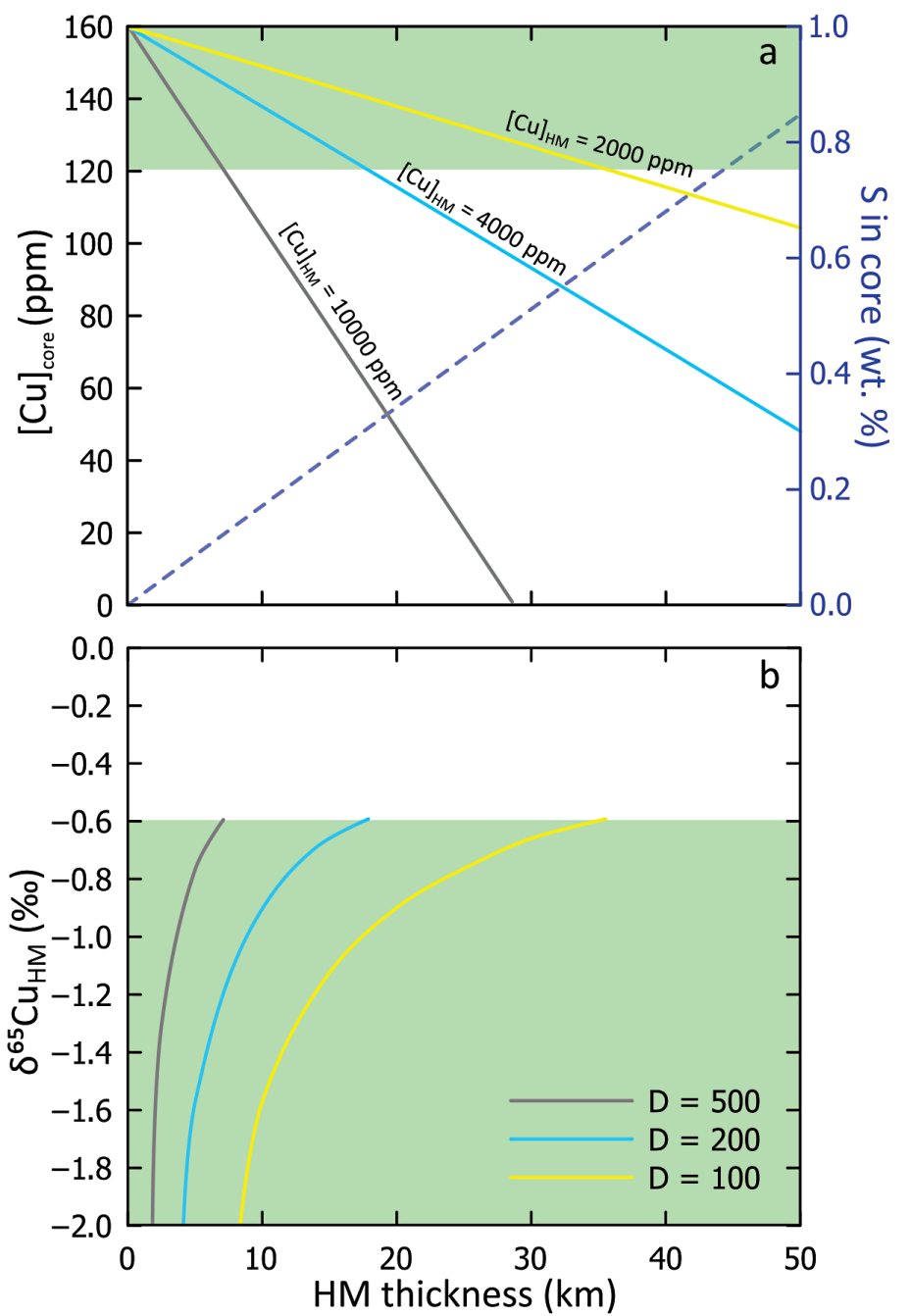

Figure 3 Results of modelled effects of removal of a "Hadean Matte" from the mantle. The effects on a) $\mathrm{Cu}$ concentration of Earth's core and b) required $\mathrm{Cu}$ isotope composition of the HM to produce a modern-day $\delta^{65} \mathrm{Cu}_{B S E}-$ plotted as a function of the thickness of the HM. D is the sulphide-silicate Cu partition coefficient. a) Green box defines "allowed" Cu concentrations of Earth's core; [Cu core < 120 ppm do not comply with the siderophile nature of Cu during core formation. Blue dotted line describes the amount of $S$ added to the core (in wt.\%) in the case of total mixing of the HM composed of a stoichiometric Fe-O-S liquid into the core. b) Lines plotted here limited to those "allowed" in top panel. 

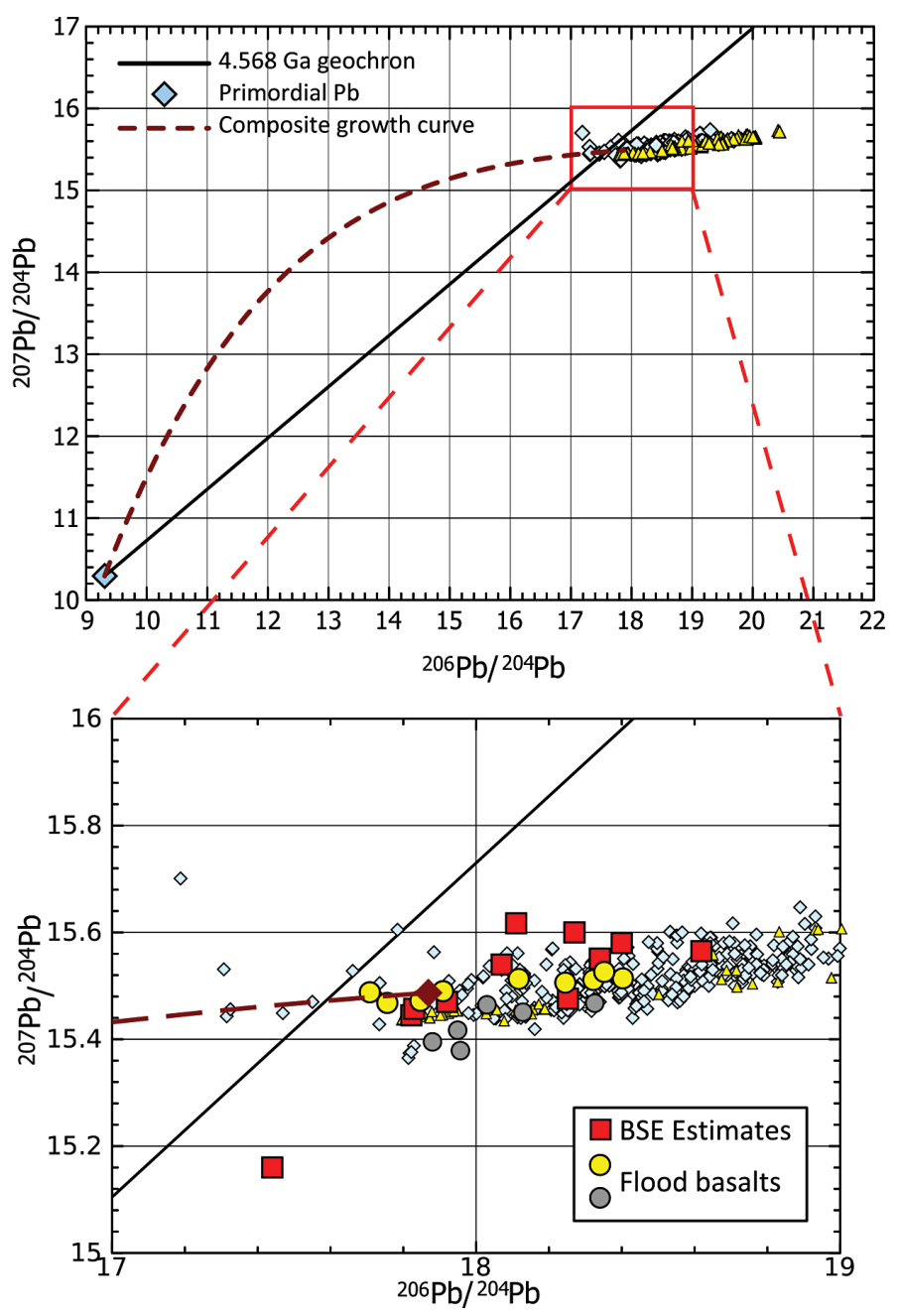

Figure 4 Modelled evolution of mantle $\mathrm{Pb}$ isotope composition as a result of $\mathrm{Pb}$ partitioning into the core at $50 \mathrm{Ma}$ and the $\mathrm{HM}$ at $100 \mathrm{Ma}$ (composite growth curve). Compilation of mid-ocean ridge basalt (MORB) and ocean island basalt (OIB) data taken from PetDB (http:// www.earthchem.org/petdb) which all plot to the right (more radiogenic) side of the terrestria $(4.568 \mathrm{Ga}$ ) geochron (based on the evolution of $\mathrm{Pb}$ from primordial source - based on Canyon Diablo Troilite). Lower figure is a zoom, showing that the composite curve agrees with some of the more unradiogenic estimates for modern day BSE Pb isotope composition (Halliday, 2004), as well as the compositions of certain flood basalt provinces (yellow: Ontong Java Plateau; grey: Baffin Island) thought to best represent ancient primitive mantle composition (Jackson and Carlson, 2011)
To conclude, the $\mathrm{Cu}$ isotope composition of BSE seems to require that large scale sulphide-silicate equilibration occurred sometime in Earth's history; here, we have modelled it as the formation of a discreet Fe-O-S reservoir, a "Hadean Matte", which ponded to the base of the mantle during the final stages of Earth's differentiation. Such a feature likely admixed into Earth's core; however, if any of this material remains, such material could account for recently detected nonchondritic S isotope compositions in Earth's mantle (Labidi et al., 2013). Finally, the Martian core is thought to have up to 14 wt. \% S (Wänke and Dreibus, 1994) so FeS-silicate equilibration during core formation could have a significant effect on Mars' mantle; $\mathrm{Cu}$ isotopes have the potential to identify this effect.

\section{Acknowledgements}

This research was supported by the Marie Curie IOF Fellowship "Isovolc", funding from the European Research Council under the European Community's Seventh Framework Programme (FP7/2007-2013)/ERC grant agreement \#207467 (DECore) and under the H2020 framework program/ERC grant agreement \#637503 (Pristine), as well as the financial support of the UnivEarthS Labex program at Sorbonne Paris Cité (ANR-10-LABX-0023 and ANR-11-IDEX-0005-02). FM thanks the ANR through a chaire d'excellence Sorbonne Paris Cité and the INSU through the PNP program. ISP acknowledges support from NSF EAR0946629. The authors would like to thank Katharina Lodders, Bruce Fegley, Astrid Holzheid and Kevin Burton for discussions, Juliens Foriel and Moureau for analytical support, and Manuel Moreira, Euan Nisbet, Gary Byerly, Tim Elliott, Fang-Zhen Teng, and Rosalind Helz for sample provision. Three anonymous reviewers and executive editor Graham Pearson greatly improved the text.

Editor: Graham Pearson

\section{Additional Information}

Supplementary Information accompanies this letter at www.geochemicalperspectivesletters.org/article1506

Reprints and permission information is available online at http://www. geochemicalperspectivesletters.org/copyright-and-permissions

Cite this letter as: Savage, P.S., Moynier, F., Chen, H., Siebert, J., Badro, J., Puchtel, I.S., Shofner, G. (2015) Copper isotope evidence for large-scale sulphide fractionation during Earth's differentiation. Geochem. Persp. Let. 1, 53-64. 


\section{Author Contributions}

P.S. and F.M. conceived the study and organised sample acquisition, F.M. and H.C. implemented the $\mathrm{Cu}$ isotopic analyses and improved the methods, P.S. and H.C. produced all of the $\mathrm{Cu}$ isotope data. P.S. produced all of the tables and figures and wrote the majority of the text. G.S., J.S. and J.B. designed and performed the high pressure experiments, performed electron probe analyses and wrote the experimental methods section. I.P. provided the komatiite samples. All of the authors were involved in critiquing the work during its authorship.

\section{References}

ALBARÈDE, F. (2009) Volatile accretion history of the terrestrial planets and dynamic implications. Nature 461, 1227-1233.

ARndT, N. (2008) Komatiite. First edition, Cambridge University Press, United Kingdom.

BADRO, J., COTE, A.S., BRODHOLT, J.P. (2014) A seismologically consistent compositional model of Earth's core. Proceedings of the National Academy of Science 111, 7542-7545.

Burton, K.W., Cenki-Tok, B., Mokadem, F., Harvey, J., Gannoun, A., Alard, O., Parkinson, I.J. (2012) Unradiogenic lead in Earth's upper mantle. Nature Geoscience 5, 570-573.

Chen, H., Savage, P.S., Teng, F.-Z., Helz, R.T., Moynier, F. (2013) Zinc isotope fractionation during magmatic differentiation and the isotopic composition of the bulk Earth. Earth and Planetary Science Letters 369-370, 34-42.

Dauphas, N., Chen, J.H., Zhang, J., Papanastassiou, D.A., Davis, A.M., Travaglio, C. (2014) Calcium- 48 isotopic anomalies in bulk chondrites and achondrites: Evidence for a uniform isotopic reservoir in the inner protoplanetary disk. Earth and Planetary Science Letters 407, 96-108.

Dreibus, G., PALME, H. (1996) Cosmochemical constraints on the sulphur content in the Earth's core. Geochimica et Cosmochimica Acta 60, 1125-1130.

Fitoussi, C., BourDon, B. (2012) Silicon isotope evidence against an enstatite chondrite earth Science 335, 1477-1480.

GALER, S.J.G., GoldSTEIN S.L. (1996) Influence of accretion on lead in the Earth. In: Basu, A., Hart S. (Eds.) Earth Processes: Reading the Isotopic Code, AGU Geophysical Monograph 95, 75-98.

HALLIDAY, A.N. (2004) Mixing, volatile loss and compositional change during impact-driven accretion of the Earth. Nature 427, 505-509.

HerwartZ, D., PACK, A., FriedrichS, B., BISCHOfF, A. (2014) Identification of the giant impactor Theia in lunar rocks. Science 344, 1146-1150.

Holzheid, A., Sylvester, P., O’Neill, H.St.C., Rubie, D.C., Palme, H. (2000) Evidence for a late chondritic veneer in the Earth's mantle from high-pressure partitioning of palladium and platinum. Nature 406, 396-399.

JACKSON, M.G., CARLSON, R. (2011) An ancient recipe for flood basalt genesis. Nature 476, 316-319 Kleine, T., Palme, H., Mezger, K., Halliday, A.N. (2005) Hf-W chronometry of lunar metals and the age and early differentiation of the Moon. Science 310, 1671-1674

KRAMERS, J.D., TOLSTIKHIN, I.N. (1997) Two terrestrial lead isotope paradoxes, forward transpor modelling, core formation and the history of the continental crust. Chemical Geology 139, 75-110.

Labidi, J., CARTignY, P., Moreira, M. (2013) Non-chondritic sulphur isotope composition of the terrestrial mantle. Nature 501, 208-211.
LeE, C.-T.A., Luffi, P., Chin, E.J., Bouchet, R., Dasgupta, R., Morton, D.M., Le Roux, V., YIN, Q.-Z., JIN, D. (2012) Copper systematics in arc magmas and implications for crust-mantle differentiation. Science $335,64-66$.

LODDERS, K. (2003) Solar System abundances and condensation temperatures of the elements. Astrophysical Journal Letters 591, 1220-1247.

LuCK, J.M., Ben Othman, D., AlbaRÈDE., F. (2005) Zn and Cu isotopic variations in chondrites and iron meteorites: Early solar nebula reservoirs and parent-body processes. Geochimica et Cosmochimica Acta 69, 5351-5363.

MarKL, G., LAHAYE, Y., Schwinn, G. (2006) Copper isotopes as monitors of redox processes in hydrothermal mineralization. Geochimica et Cosmochimica Acta 70, 4215-4228.

MCDonOUGH, W.F. (2003) Compositional model for the Earth's core. In: Carlson, R.W. (Ed) The mantle and core, Treatise on Geochemistry, $1^{\text {st }}$ edition, 2, 547-568.

O'NeILL, H.ST.C. (1991) The origin of the moon and the early history of the earth - A chemical model. Part 2: The earth. Geochimica et Cosmochimica Acta 55, 1159-1172.

Palme, H., O'Neill, H.St.C. (2014) Cosmochemical estimates of mantle composition. In: Carlson R.W. (Ed) The mantle and core, Treatise on Geochemistry, $2^{\text {nd }}$ edition, 3, 1-39.

POIRIER, J.-P. (1994) Light elements in the Earth's outer core: A critical review. Physics of the Earth and Planetary Interiors 85, 319-337.

SCHÖnbächler, M., Carlson, R.W., Horan, M.F., Mock, T.D., Hauri, E.H. (2010) Heterogeneous accretion and the moderately volatile element budget of Earth. Science 328, 884-887.

Siebert, J., BADRo, J., ANTONANGeli, D., RYERSON, F.J. (2013) Terrestrial accretion under oxidizing conditions. Science 339, 1194-1197.

WADE, J., WoOD, B.J., TuFF, J. (2012) Metal-silicate partitioning of Mo and W at high pressures and temperatures: Evidence for late accretion of sulphur to the Earth. Geochimica et Cosmochimica Acta 85, 58-74.

WANG, Z., BECKER, H. (2013) Ratios of S, Se and Te in the silicate Earth require a volatile-rich late veneer. Nature 499, 328-331.

WÄNKE, H., DREIBUS, G. (1994) Chemistry and accretion history of Mars. Philosophical Transaction of the Royal Society of London Series A 349, 285-293.

WiLLIAMS, H.M., ARCHER, C. (2011) Copper stable isotopes as tracers of metal-sulphide segregation and fractional crystallisation processes on iron meteorite parent bodies. Geochimica et Cosmochimica Acta 75, 3166-3178

WOOD, B.J., HALLiDAY, A.N. (2005) Cooling of the Earth and core formation after the giant impact. Nature 437, 1345-1348. 